\title{
Blocking of programmed death ligand 1 enhances natural killer cell-mediated immunity against malignant melanoma cells
}

\section{Young-shin Lee}

Pusan National University School of Medicine

Woong Heo

Pusan National University School of Medicine

Ho-Jung Choi

Pusan National University School of Medicine

Hae-Ryung Cho

Pusan National University School of Medicine

Ji Ho Nam

Pusan National University Yangsan Hospital

\section{Yong Gan Ki}

Pusan National University Yangsan Hospital

Chi Dug Kang

Pusan National University School of Medicine

Jaeho Bae ( $\sim$ biosole@pusan.ac.kr)

https://orcid.org/0000-0002-7077-6555

\section{Research article}

Keywords: NKG2D ligands, ionizing radiation, programmed death-1, natural killer cell

Posted Date: March 5th, 2020

DOI: https://doi.org/10.21203/rs.3.rs-16217/v1

License: (1) (1) This work is licensed under a Creative Commons Attribution 4.0 International License. Read Full License 


\section{Abstract}

Background Since ionizing radiation has showed the dramatic effect to kill the cancer cells by direct DNA damage as well as triggering anti-cancer immune responses through release of various tumor antigens and induction of NK activating molecules, it has been used for long time to treat many cancer patients including patients with melanoma. However, it has been known that radiotherapy might promote the remnant cancer cells to escape immune system. One of the suggested ways is induction of a ligand for programmed death-1 (PD-L1) after radiotherapy in head and neck cancer, bladder cancer and lung cancer cells which engages the receptor, programmed death-1 (PD-1) in immune cells. PD-1/PD-L1 axis transduces the inhibitory signal and suppresses the adaptive immunity in T cells. However, their role in innate immunity remains poorly understood. Therefore, we investigated whether ionizing radiation could change the expression of PD-L1/2 in malignant melanoma cells and the receptor, PD-1, in NK-92 cells. Results Surface PD-L1/2 levels on melanoma cells were increased by ionizing radiation in a dosedependent manner but the level of PD-L1 was not changed significantly in NK-92 cells. Radiation-induced PD-L1/2 suppressed the activity of the NK-92 cells against melanoma cells despite of upregulation of NKG2D ligands. Furthermore, activated NK cells had high level of PD-1 and could not kill PD-L1/2+ melanoma cells effectively. When we used PD-L1 inhibitor or silenced PD-L1 gene to inhibit PD-1/PD-L1 axis, they reversed the activity of the suppressed NK cells. Conclusions Through these results, we supposed that PD-1/PD-L1 blockade could enhance the immune responses of NK cells against melanoma cells after radiotherapy and might overcome the PD-L1 mediated radioresistance of cancer cells.

\section{Background}

Radiotherapy is a major modality in treatment of most common cancers including melanoma. Both proand anti-cancer immune responses could be induced in cancer microenvironment after radiation. The anti-cancer immune responses are observed in some cancers. Several immune stimulation genes such as TNF-a were upregulated and antigenic proteins such as HSPs were released after radiotherapy in bulky cancers and glioblastoma[1-3]. However, it was known more recently that radiation promotes the remnant cancer cells to escape immune system and distant metastasis through the increased expression of TGF$\beta$, PD-L1 and MMP-2 in cancer cells [4-6]. Furthermore, ionizing radiation may alter the anti-cancer activity of lymphocytes through dysregulation of immune check points molecules such as PD-1 and CTLA-4[7, 8]. Therefore, these adverse effects of radiotherapy should be considered and managed to treat the cancer patients. Since it was known that radiotherapy could induce the PD-L1 in several cancer cells including Head and Neck Squamous Cell Carcinoma, bladder cancer and Non-Small Cell Lung Cancer [9-11], it was supposed that PD-1/PD-L1 axis blockade was required to inhibit the adverse effect of radiotherapy and may be benefit to treat cancer patients.

NK cells are critical innate immune lymphocytes which destroy virally infected or cancerous cells through targeted cytotoxicity [12]. Interestingly, we found that NK cells expressed PD-1 on cell surface and the level of PD-1 increased significantly during their activation. Therefore, it was supposed that NK cell- 
mediated immune responses were controlled by the level of PD-1 as if the cancer reactive T cells did and its blockade might be required to obtain the sufficient anti-cancer immunity. In this study, we evaluated the efficacy on NK cell-mediated anticancer immune responses after irradiation and investigated the role of PD-1/PD-L1 axis in NK cells.

\section{Results}

\section{Surface PD-L1 and PD-L2 were increased by ionizing radiation with dosedependent manner in melanoma cells}

The surface expression of PD-L1/2 in melanoma cells was detected using PE-conjugated anti-PD-L1/2 antibodies and analyzed by flow cytometry. The expression level of PD-L1 was relatively higher than PDL2 in A375 cells and SK-MEL-28 cells. The expression of PD-L1 and PD-L2 were increased following 8 Gy and $16 \mathrm{~Gy}$ irradiation in a dose-dependent manner in two melanoma cells (Fig.1). It was suggested that ionizing radiation may be a potent inducer of two ligands of PD-1 and high dose irradiation may have adverse effects in anti-cancer immunity.

\section{The Expression NKG2D ligands increased by ionizing radiation in melanoma cells}

The surface expression of NKG2D ligands including MICA, MICB and ULBP1-3 were detected using mouse anti-human specific antibodies and goat PE-conjugated anti-mouse IgG secondary antibodies. The expression of five NKG2D ligands were increased following 8 Gy irradiation in two melanoma cells (Fig.2). It was well known that the DNA damage agents including ionizing radiation could increase the NKG2D ligands by facilitation protein translation through ATM-ATR pathway[13]. We confirmed the same radiation effects on melanoma cells.

\section{The expression of PD-1 increased dramatically during activation of NK-92 cells}

Although NK-92 cells in steady state expressed a little amount of PD-1 (Fig.3A), the expression of PD-1 was dramatically increased when they are stimulated by K562 cells (Fig.3B). It seems that active NK cells might be intrinsically suppressed to prevent uncontrolled immune responses by induction of PD-1 and it makes be hard to maintain the potent cytotoxic activity for sufficient time against cancer cells physiologically. Therefore, it was supposed that PD-L $1^{\text {high }}$ cancer cells might survive we through escape from NK cell-mediated immune responses.

\section{The susceptibility of melanoma cells to NK cells is increased by PD-L1 inhibitor.}

The high expression of PD-L1 in melanoma cells and increased PD-1 in NK cells might repress the activity of NK cells after short period of action and it seems insufficient time to eliminate melanoma cells. We investigated whether anti-cancer immune responses against melanoma cells could be affected by using PD-L1 or PD-1 inhibitor. Under the various experimental conditions, susceptibility of melanoma cells to NK-92 cells was significantly enhanced by inhibition of PD-1/PD-L1 axis (Fig.4). 


\section{Discussion}

The immune checkpoint PD-1 is expressed on many cancer infiltrating lymphocytes in response to inflammation. The engagement of PD-1 on the lymphocyte by PD-L1 on melanoma cells downregulates T-cell function and might promote exhaustion of cancer reactive T cells $[14,15]$. The usage of anti-PD-1 and anti-PD-L1 antibodies has been remarkably successful, both in terms of response rates $(30 \%-45 \%)$ and durability (2-3 years) in melanoma[16-24], even after discontinuation of the treatments[24, 25]. These enthusiastic studies about PD-1/PD-L1 have been focused on adaptive immune cells, especially $T$ cells. The role and regulation of PD-1/PD-L1 in innate immunity remains poorly understood until now.

Recent emerging data indicate that combining PD-L1 inhibitors with other therapies including chemotherapy, radiotherapy and immunotherapy might be more beneficial to cure cancer patients[26-28] and we already have been studied that ionizing radiation was efficient modality to trigger NK cellmediated immune responses[29]. Therefore, we evaluated the efficacy on NK cell-mediated anticancer immune responses by the combination with PD-L1 inhibitor.

Activation of NK cells rapidly induced PD-1 receptor on their surface and irradiated melanoma cells also expressed high level of ligands of PD-1. Therefore, it was supposed that the blockade of PD-1/PD-L1 was required to maintain the NK cell-mediated anti-cancer immunity against melanoma cells. We used the ionizing radiation to trigger the immune responses against melanoma cells by induction of NKG2D ligands, a kind of NK cell activating molecules. It was known that radiotherapy could induce the PD-L1 in several cancer cells including HNSCC, bladder cancer and NSCLC[9-11]. However, the mechanisms to induce the PD-L1 is not understood yet. It required more sophisticated strategies to find clues to resolve it.

Taking into account these facts, we hypothesized that blocking of programmed death ligand 1 could enhance natural killer cell-mediated anticancer immunity to melanoma cell lines.

\section{Conclusions}

We have examined the level of PD-1/PD-L1 expression on NK cells and melanoma cells by ionizing radiation, respectively. lonizing radiation could increase the expression of surface PD-L1 and it supressed the susceptibility of melanoma cells to NK cells though NKG2D ligands expression was increased by ionizing radiation. However, PD-1 or PD-L1 inhibitor enhanced susceptibility to NK cells by inhibition of PD-1/PD-L1 axis. Taken together these results, the blockade of PD-1 could enhance NK cell-mediated anticancer immunity to melanoma cells.

\section{Methods}

\section{Cell Lines and Reagents}

A375P and SK-MEL-28 are human melanoma cell lines was used in this study which was obtained from the American Type Culture Collection (Rockville, MD, USA). These cell lines were maintained in DMEM 
media supplemented with $10 \%$ fetal bovine serum (FBS) (Gibco, Grand Island, NY), 2 mM L-glutamine, $100 \mathrm{mg} / \mathrm{ml}$ streptomycin, and $100 \mathrm{U} / \mathrm{ml}$ penicillin. the NK-92 cell line was obtained from American Type Culture Collection (Rockville, MD, USA) and maintained in a -Minimum Essential Modified medium supplemented with $12.5 \%(\mathrm{v} / \mathrm{v})$ fetal bovine serum, $12.5 \%(\mathrm{v} / \mathrm{v})$ horse serum, $2 \mathrm{mM}$ L-glutamine, $0.1 \mathrm{mM}$ 2-mercaptoethanol, $200 \mathrm{U} / \mathrm{mL}$ of recombinant human interleukin-2, $100 \mathrm{mg} / \mathrm{mL}$ streptomycin, and 100 $\mathrm{U} / \mathrm{mL}$ penicillin. All cell lines were cultured at $37^{\circ} \mathrm{C}$ in a humidified atmosphere containing $5 \% \mathrm{CO} 2$.

\section{Flow cytometry.}

Mouse anti-human CD273(PD-L2; \#345505), CD274(PD-L1; \#329709), CD279(PD-1; \#329911) antibodies were purchased from BioLegend. Cell-surface staining was performed by incubating tumor-derived cell populations with selected antibodies on ice in the dark for 30 minutes in PBS. To determine the surface PD-L1/2, PD-1 on cancer cells, the analysis was performed using BD FACSCanto ${ }^{\mathrm{TM}}$ II (Becton Dickinson, San Jose, CA USA). The data was analyzed by the Flowjo software (TreeStar, OR, USA) and the expression levels were determined by the Mean Fluorescence Intensity (MFI).

\section{Irradiation and combination with PD-L1 inhibitor}

To irradiate the cancer cells, ClinaciX Linear Accelerator (Varian Medical Systems Inc., Palo Alto, CA, USA) was used under consults of Dr. Jiho Nam and Yong Gan Ki (Pusan National University Yangsan Hospital). The cells were irradiated with rate of $8 \mathrm{~Gy} / \mathrm{min}$ under $10 \mathrm{~mm}$ depth-coverage of medium. Irradiated melanoma cells were recovered for 6 hours and then, PD-L1 inhibitor were treated. After further incubation for 18 hours, the cells were collected to other assays.

\section{NK cell-mediated cytotoxicity.}

NK cell-mediated cytotoxicity was determined using flow cytometry. The melanoma cells were stained with $50 \mathrm{mM}$ carboxyfluorescein succinimidyl ester (CFSE) for $30 \mathrm{~min}$ at $37^{\circ} \mathrm{C}$ and washed three times. NK-92 cells and CFSE-stained melanoma cells were co-cultured for 4 hours. Propidium iodide (PI) was added to the co-cultured samples for identification of the dead cells. Cytotoxicity were calculated by formula of $\left(\mathrm{CFSE}^{+} \mathrm{PI}^{+}\right.$cells / $\mathrm{CFSE}^{+}$cells) X $100(\%)$.

\section{Abbreviations}

ATM: Ataxia telangiectasia mutated protein; ATR: Ataxia telangiectasia and Rad3-related protein; CTLA-4: Cytotoxic T lymphocyte associated protein 4; HNSCC: Head and neck squamous cell carcinoma; HSP: Heat shock protein; IgG: Immunoglobulin G; MIC: MHC class 1 chain-related protein; MMP: Matrix metalloproteinase; NK: Natural killer; NKG2D: Natural killer group 2, member D; NSCLC: Non-small cell lung cancer; PD-1: Programmed death receptor-1; PD-L1: Programmed death ligand-1; PE: Phycoerythrin; TNF-a: Tumor necrosis factor-alpha; TGF-b: Tumor growth factor-beta; ULBP: UL16 binding protein

\section{Declarations}




\section{Acknowledgement}

This work was supported by a Pusan National University Research Grant for 2 years.

\section{Availability of data and materials}

The datasets used and/or analyzed during the current study are available from the corresponding author on reasonable request.

\section{Authors' contributions}

YSL performed experiments and wrote the manuscript. HJC, and HRC performed experiments, including flow cytometry and cytotoxicity assay. WH performed statistical analysis. JHN and YGK performed ionizing radiation. CDK developed the platform of multiplex PCR for NKG2D ligands. JB designed and evaluated the study. All the authors read and approved the final version.

\section{Competing interests}

The authors declare that they have no competing interests.

\section{Funding}

Not applicable.

\section{Ethics approval and consent to participate}

Not applicable.

\section{Consent for publication}

Not applicable

\section{Authors' information (optional)}

${ }^{a}$ Department of Biochemistry, Pusan National University School of Medicine, Yangsan, 50162, South Korea.

${ }^{b}$ Department of Molecular cell biology and genetics, PNU BK21 Plus Biomedical Science Education Center, Pusan National University School of Medicine, Yangsan, 50612, Korea.

'Department of Radiation Oncology, Pusan National University School of Medicine, Yangsan, 50162, South Korea.

\section{References}


1. Matsumoto H, Wang XJ, Ohnishi T: Binding between Wild-Type P53 and Hsp72 Accumulated after Uv and Gamma-Ray Irradiation. Cancer letters 1995, 92(2):127-133.

2. Sathishkumar S, Dey S, Meigooni AS, Regine WF, Kudrimoti MS, Ahmed MM, Mohiuddin M: The impact of TNF-alpha induction on therapeutic efficacy following high dose spatially fractionated (GRID) radiation. Technology in cancer research \& treatment 2002, 1(2):141-147.

3. Multhoff G, Pockley AG, Schmid TE, Schilling D: The role of heat shock protein 70 (Hsp70) in radiation-induced immunomodulation. Cancer letters 2015, 368(2):179-184.

4. Barcellos-Hoff MH, Cucinotta FA: New tricks for an old fox: impact of TGFbeta on the DNA damage response and genomic stability. Science signaling 2014, 7(341):re5.

5. Dovedi SJ, Adlard AL, Lipowska-Bhalla G, McKenna C, Jones S, Cheadle EJ, Stratford IJ, Poon E, Morrow M, Stewart R et al: Acquired Resistance to Fractionated Radiotherapy Can Be Overcome by Concurrent PD-L1 Blockade. Cancer Res 2014, 74(19):5458-5468.

6. Ekinci T, Ozbay PO, Yigit S, Yayuzcan A, Uysal S, Soylu F: The correlation between immunohistochemical expression of MMP-2 and the prognosis of epithelial ovarian cancer. Ginekol Pol 2014, 85(2):121-130.

7. Park SS, Dong HD, Liu X, Harrington SM, Krco CJ, Grams MP, Mansfield AS, Furutani KM, Olivier KR, Kwon ED: PD-1 Restrains Radiotherapy-Induced Abscopal Effect. Cancer Immunol Res 2015, 3(6):610-619.

8. Liu SZ, Jin SZ, Liu XD, Sun YM: Role of CD28/B7 costimulation and IL-12/IL-10 interaction in the radiation-induced immune changes. BMC immunology 2001, 2:8.

9. Schulz D, Stancev I, Sorrentino A, Menevse AN, Beckhove P, Brockhoff G, Hautmann MG, Reichert TE, Bauer RJ, Ettl T: Increased PD-L1 expression in radioresistant HNSCC cell lines after irradiation affects cell proliferation due to inactivation of GSK-3beta. Oncotarget 2019, 10(5):573-583.

10. Wu CT, Chen WC, Chang YH, Lin WY, Chen MF: The role of PD-L1 in the radiation response and clinical outcome for bladder cancer. Scientific reports 2016, 6:19740.

11. Shen MJ, Xu LJ, Yang L, Tsai Y, Keng PC, Chen Y, Lee SO, Chen Y: Radiation alters PD-L1/NKG2D ligand levels in lung cancer cells and leads to immune escape from NK cell cytotoxicity via IL-6MEK/Erk signaling pathway. Oncotarget 2017, 8(46):80506-80520.

12. Biron CA, Byron KS, Sullivan JL: Severe herpesvirus infections in an adolescent without natural killer cells. The New England journal of medicine 1989, 320(26):1731-1735.

13. Gasser S, Orsulic S, Brown EJ, Raulet DH: The DNA damage pathway regulates innate immune system ligands of the NKG2D receptor. Nature 2005, 436(7054):1186-1190.

14. Yokosuka T, Takamatsu M, Kobayashi-Imanishi W, Hashimoto-Tane A, Azuma M, Saito T:

Programmed cell death 1 forms negative costimulatory microclusters that directly inhibit $T$ cell receptor signaling by recruiting phosphatase SHP2. The Journal of experimental medicine 2012, 209(6):1201-1217.

15. Hui E, Cheung J, Zhu J, Su X, Taylor MJ, Wallweber HA, Sasmal DK, Huang J, Kim JM, Mellman I et al: T cell costimulatory receptor CD28 is a primary target for PD-1-mediated inhibition. Science 2017, 
355(6332):1428-1433.

16. Topalian SL, Hodi FS, Brahmer JR, Gettinger SN, Smith DC, McDermott DF, Powderly JD, Carvajal RD, Sosman JA, Atkins MB et al: Safety, activity, and immune correlates of anti-PD-1 antibody in cancer. The New England journal of medicine 2012, 366(26):2443-2454.

17. Hamid O, Robert C, Daud A, Hodi FS, Hwu WJ, Kefford R, Wolchok JD, Hersey P, Joseph RW, Weber JS et al: Safety and tumor responses with lambrolizumab (anti-PD-1) in melanoma. The New England journal of medicine 2013, 369(2):134-144.

18. Robert C, Ribas A, Wolchok JD, Hodi FS, Hamid O, Kefford R, Weber JS, Joshua AM, Hwu WJ, Gangadhar TC et al: Anti-programmed-death-receptor-1 treatment with pembrolizumab in ipilimumab-refractory advanced melanoma: a randomised dose-comparison cohort of a phase 1 trial. Lancet 2014, 384(9948):1109-1117.

19. Topalian SL, Sznol M, McDermott DF, Kluger HM, Carvajal RD, Sharfman WH, Brahmer JR, Lawrence DP, Atkins MB, Powderly JD et al: Survival, durable tumor remission, and long-term safety in patients with advanced melanoma receiving nivolumab. Journal of clinical oncology : official journal of the American Society of Clinical Oncology 2014, 32(10):1020-1030.

20. Ribas A, Puzanov I, Dummer R, Schadendorf D, Hamid O, Robert C, Hodi FS, Schachter J, Pavlick AC, Lewis KD et al: Pembrolizumab versus investigator-choice chemotherapy for ipilimumab-refractory melanoma (KEYNOTE-002): a randomised, controlled, phase 2 trial. The Lancet Oncology 2015, 16(8):908-918.

21. Robert C, Long GV, Brady B, Dutriaux C, Maio M, Mortier L, Hassel JC, Rutkowski P, McNeil C, KalinkaWarzocha E et al: Nivolumab in previously untreated melanoma without BRAF mutation. The New England journal of medicine 2015, 372(4):320-330.

22. Robert C, Schachter J, Long GV, Arance A, Grob JJ, Mortier L, Daud A, Carlino MS, McNeil C, Lotem M et al: Pembrolizumab versus Ipilimumab in Advanced Melanoma. The New England journal of medicine 2015, 372(26):2521-2532.

23. Ribas A, Hamid O, Daud A, Hodi FS, Wolchok JD, Kefford R, Joshua AM, Patnaik A, Hwu WJ, Weber JS et al: Association of Pembrolizumab With Tumor Response and Survival Among Patients With Advanced Melanoma. Jama 2016, 315(15):1600-1609.

24. Eggermont AMM, Crittenden M, Wargo J: Combination Immunotherapy Development in Melanoma. American Society of Clinical Oncology educational book American Society of Clinical Oncology Annual Meeting 2018, 38:197-207.

25. Robert C, Ribas A, Hamid O, Daud A, Wolchok JD, Joshua AM, Hwu WJ, Weber JS, Gangadhar TC, Joseph RW et al: Durable Complete Response After Discontinuation of Pembrolizumab in Patients With Metastatic Melanoma. Journal of clinical oncology : official journal of the American Society of Clinical Oncology 2018, 36(17):1668-1674.

26. Gong J, Le TQ, Massarelli E, Hendifar AE, Tuli R: Radiation therapy and PD-1/PD-L1 blockade: the clinical development of an evolving anticancer combination. Journal for immunotherapy of cancer $2018,6(1): 46$. 
27. Grapin M, Richard C, Limagne E, Boidot R, Morgand V, Bertaut A, Derangere V, Laurent PA, Thibaudin $M$, Fumet JD et al: Optimized fractionated radiotherapy with anti-PD-L1 and anti-TIGIT: a promising new combination. Journal for immunotherapy of cancer 2019, 7(1):160.

28. Hayashi H, Nakagawa K: Combination therapy with PD-1 or PD-L1 inhibitors for cancer. International journal of clinical oncology 2019.

29. Son CH, Keum JH, Yang K, Nam J, Kim MJ, Kim SH, Kang CD, Oh SO, Kim CD, Park YS et al: Synergistic enhancement of NK cell-mediated cytotoxicity by combination of histone deacetylase inhibitor and ionizing radiation. Radiation oncology 2014, 9:49.

\section{Figures}

A

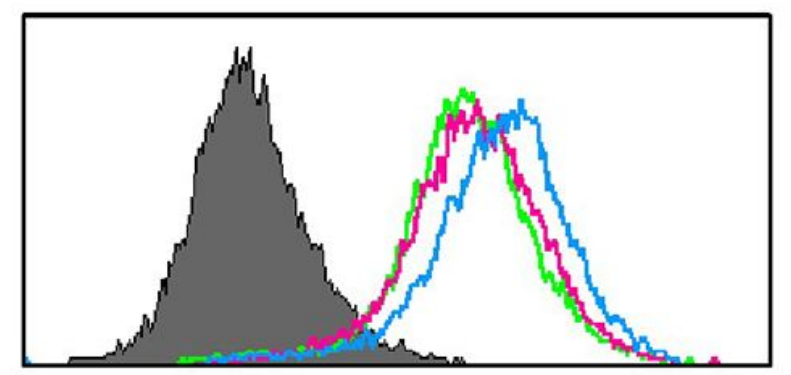

PD-L1

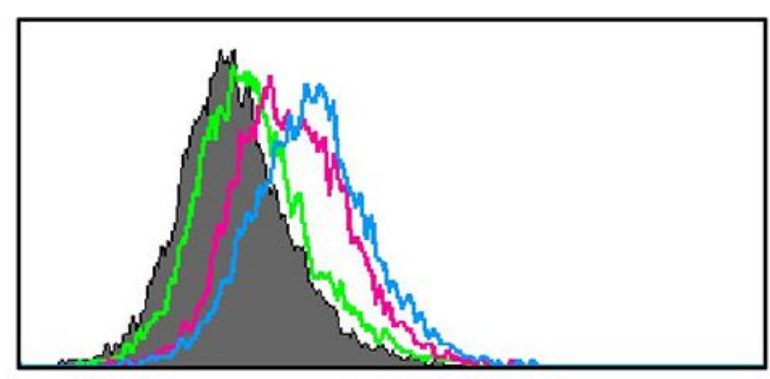

PD-L2

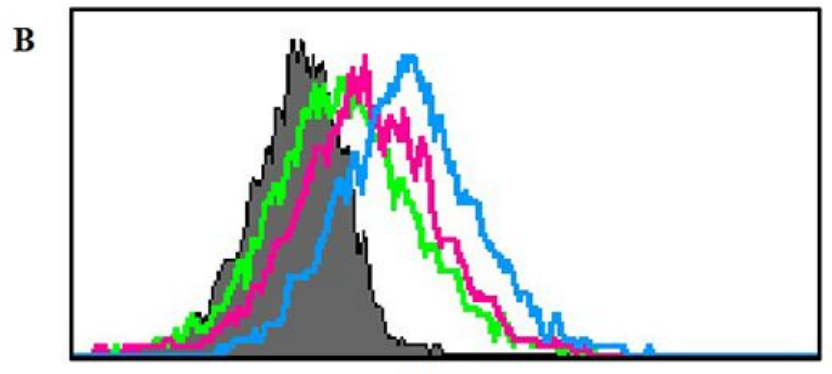

PD-L1

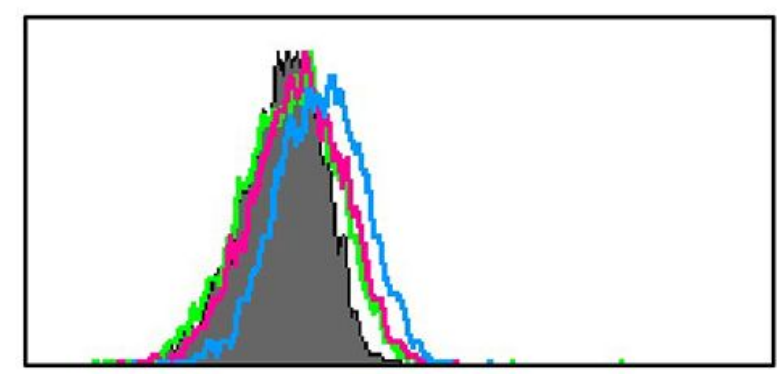

PD-L2

\section{Figure 1}

Induced surface expression of programmed death ligand 1/2(PD-L1/2) in (A)A375P and (B)SK-MEL-28 myeloma cells by ionizing radiation. (Green - Control Purple - 8Gy Blue - 16Gy) 
A

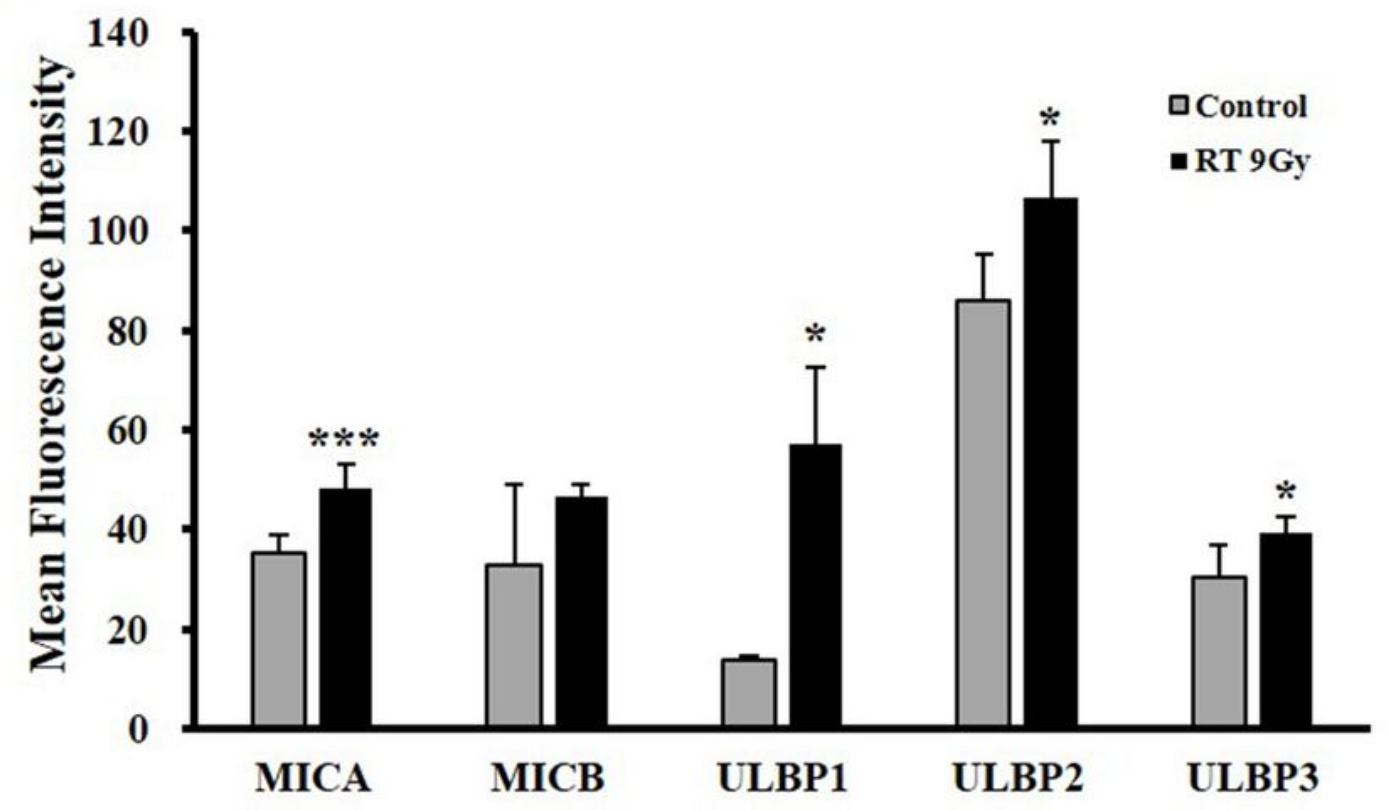

B

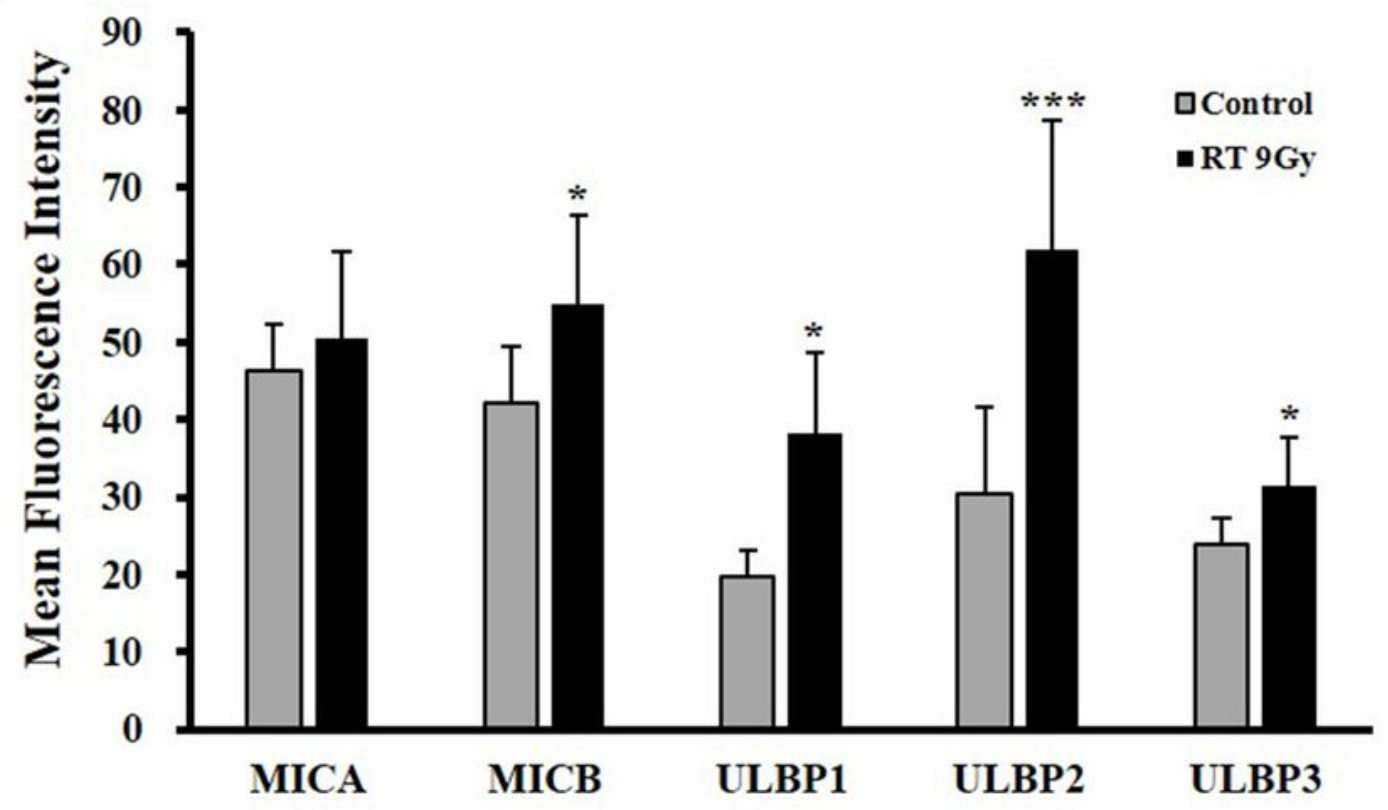

Figure 2

Induced surface expression of NKG2D ligands in (A)A375P and (B)SK-MEL-28 myeloma cells by ionizing radiation. 

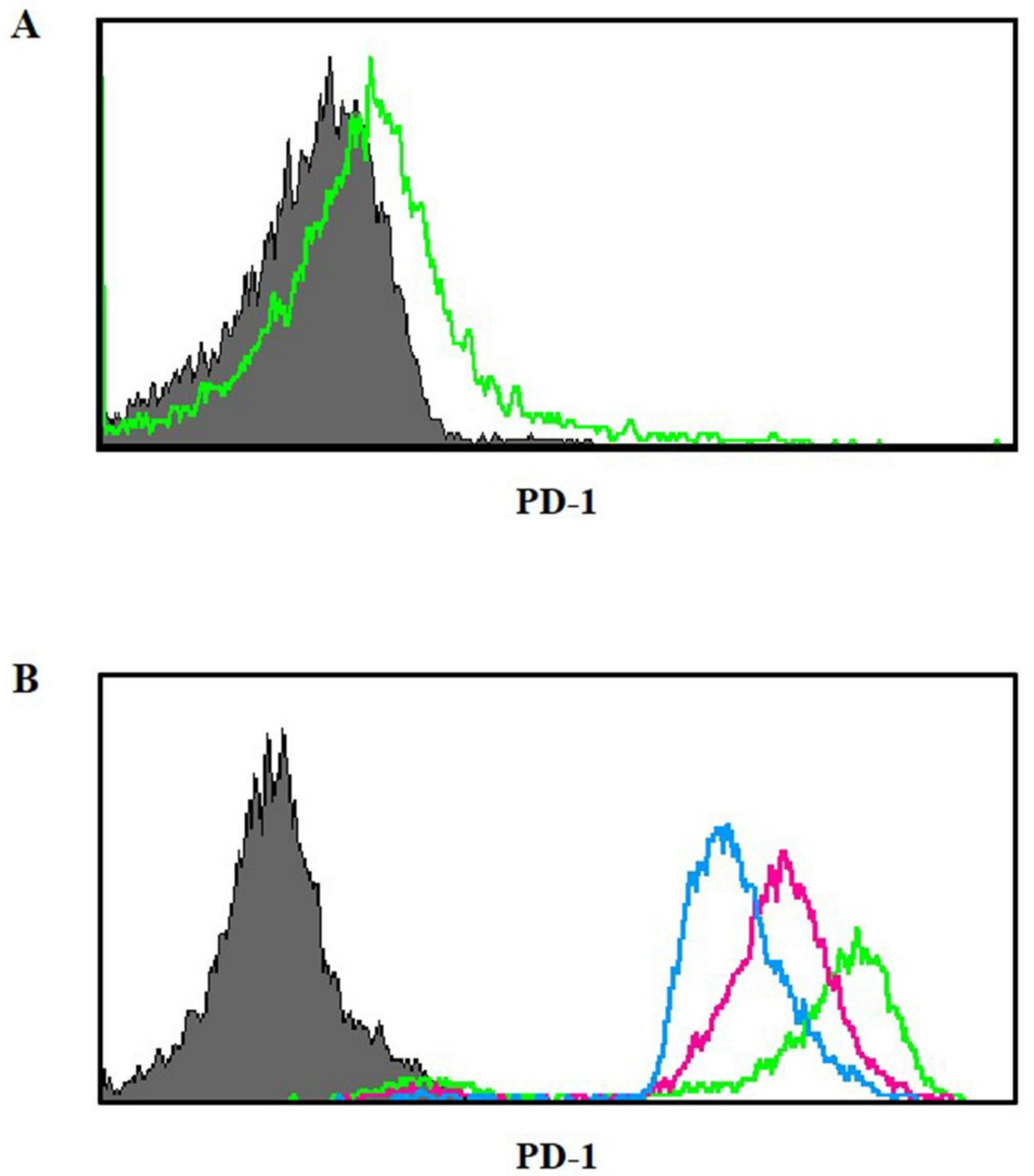

Figure 3
(A) Surface expression levels of programmed death 1 (PD-1) in steady state NK cells. (B) Surface expression of PD-1 in activated NK cells following co-culture with K562 cells. (E : T, Green - 2:1, Purple - $5: 1$, blue - 10:1) 

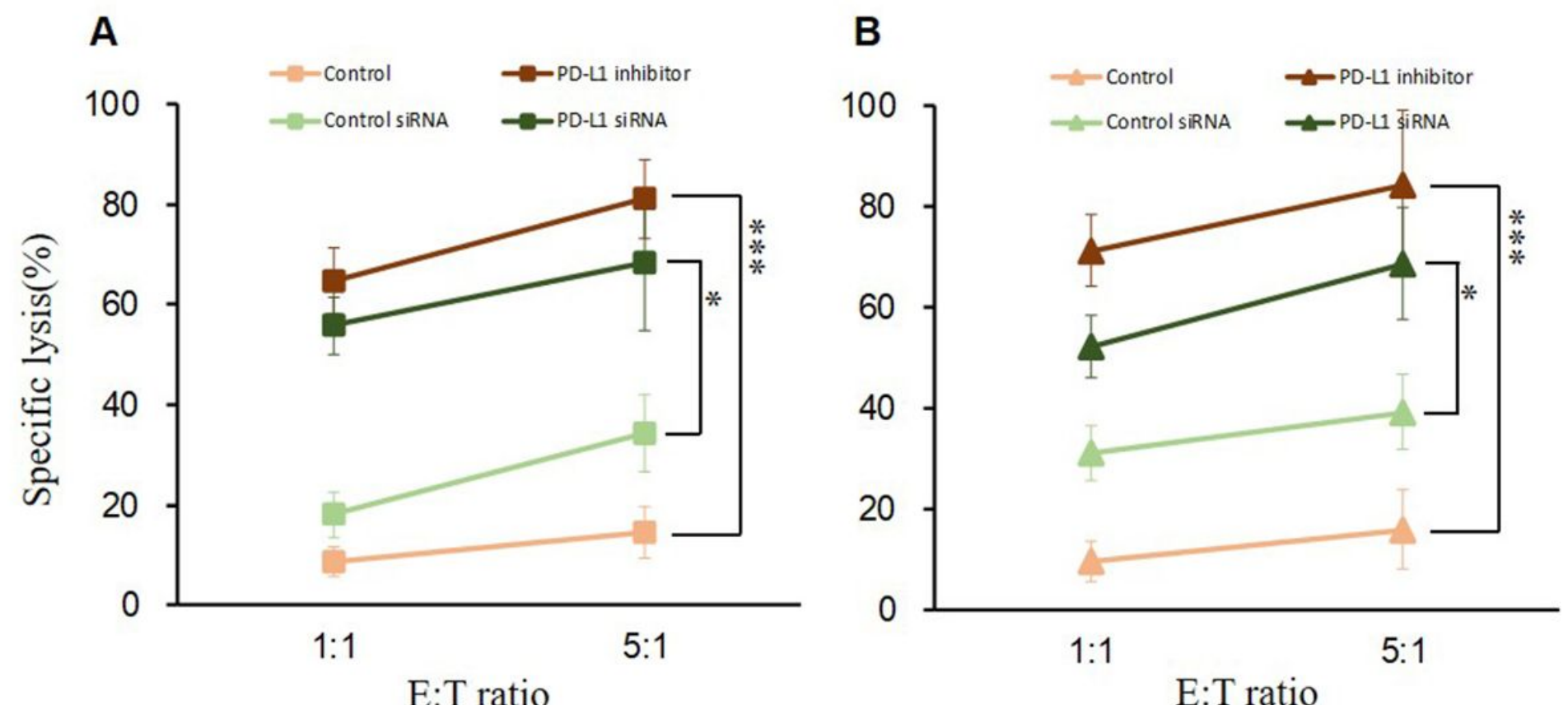

Figure 4

Enhanced susceptibility of (A)A375P and (B)SK-MEL-28 human melanoma cancer cells to NK cells by treatment with PD-L1 inhibitor or siRNA PD-L1. Light brown - Control, Light green - control siRNA, Dark green - siRNA PD-L1 and Dark brown - PD-L1 inhibitor. 